\title{
Aplicativo google classroom - ferramenta tecnológica em sala de aula
}

\author{
Google classroom app - techmology tool in the classroom \\ Google classroom application - herramienta tecnológica en la conversión de classroom
}

Recebido: 23/08/2021 | Revisado: 29/08/2021 | Aceito: 02/09/2021 | Publicado: 04/09/2021

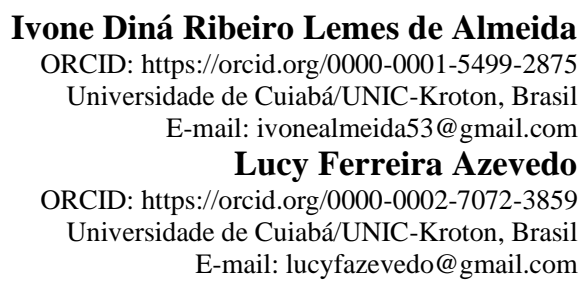

\section{Resumo}

No ano letivo de 2021, a Secretaria de Educação oportunizou aos professores da rede pública estadual de Mato Grosso, a ferramenta Google Classroom. É um recurso para o educador realizar aulas virtuais interativas e facilitar a aprendizagem. Perguntamos se, no estado mato-grossense, o docente estaria preparado para usar este recurso. Assim, o objetivo deste artigo é estudar e descrever a referida ferramenta, por meio da metodologia bibliográfica e descritiva embasado nos teóricos: Bakhtin (2003), Bronckart (2007), Chiapinotto (2010), Moran (1999) e Vigotsky (2005). Espera-se divulgar a possibilidade de associar o professor analógico ao tecnológico por meio do recurso Google Classroom.

Palavras-chave: Ensino; Educação; Aprendizagem; Aplicativo; Google classroom.

\begin{abstract}
In the 2021 school year, the Department of Education provided teachers from the state public schools of Mato Grosso with the Google Classroom tool. It is a resource for the educator to conduct interactive virtual classes and facilitate learning. We asked if, in the state of Mato Grosso, the teacher would be prepared to use this resource. Thus, the objective of this article is to study and describe this tool, through bibliographic and descriptive methodology based on theorists: Bakhtin (2003), Bronckart (2007), Chiapinotto (2010), Moran (1999) and Vigotsky (2005). It is expected to publicize the possibility of associatiating the analog teacher with the technological one through the Google Classroom feature.
\end{abstract}

Keywords: Teaching; Education; Apprenticeship; Application; Google classroom.

\section{Resumen}

En el año escolar 2021, el Departamento de Educación oportunistaizó a los maestros en la red pública estatal de Mato Grosso, la herramienta Google Classroom. Es un recurso para que el educador tome clases virtuales interactivas y facilite el aprendizaje. Preguntamos si, en el estado de Mato Grosso, el maestro estaría dispuesto a utilizar este recurso. Así, el objetivo de este artículo es estudiar y describir esta herramienta, a través de la metodología bibliográfica y descriptiva basada en los teoremas: Bakhtin (2003), Bronckart (2007), Chiapinotto (2010), Moran (1999) y Vigotsky (2005). Se espera que revele la posibilidad de asociar al profesor analógico con la tecnología a través de la función Google Classroom.

Palabras clave: Enseñanza; Educación; Aprendizaje; Aplicación; Google classroom.

\section{Introdução}

Com a evolução dos equipamentos eletrônicos, as escolas e universidades também buscam constantemente recursos tecnológicos para criar um ambiente mais dinâmico para os alunos e professores. Entre as maneiras de proporcionar um ambiente mais atrativo está a inclusão da tecnologia em sala de aula.

Existem muitas formas de inserir a tecnologia em sala de aula como, por exemplo, a adoção de ambientes virtuais/ aplicativos como Google Classroom (sala de aula), ferramentas de comunicação e equipamentos como lousa digital, 
computadores e tablets. Estudos já apontam que a inovação tecnológica inserida de forma contextualizada e alinhada com as expectativas dos estudantes e educadores pode ter benefícios importantes no desenvolvimento educacional.

O docente tornou-se responsável pela união do ensino e do acesso à tecnologia em sala de aula. Ou seja, ele é responsável por mediar o compartilhamento de conhecimento e por incentivar o processo de aprendizado. A partir da afirmação sobre a responsabilidade do professor, perguntaríamos se, no Estado de Mato Grosso, o profissional da Educação estaria preparado para utilizar tantos recursos, especialmente o google classroom (sala de aula). Surge-nos, assim, o objetivo desse estudo que é estudar e descrever a ferramenta Google Classroom, trajeto de estudo apoiado na metodologia bibliográfica e descritiva.

O papel do professor em sua concepção historicista era daquela pessoa que apenas passava o conhecimento aos estudantes. Com a tecnologia em sala de aula, a informação pode ser facilmente encontrada pelos estudantes e o trabalho do educador é reinventado.

Existem milhares de novas ferramentas que podem facilitar o desejo de aprendizado. Em sala de aula, o uso de um quadro digital demonstra claramente como a internet pode ser uma fonte de ensinamento. A maior parte das limitações de duas décadas atrás caíram por terra.

Há conhecimentos que deixaram de ser essenciais e foram assumidos por máquinas. Já outros, mais conscientes, ganharam um novo poder. Aprender a utilizar uma plataforma ou ferramenta, por exemplo, permite avançar em uma ocupação ou atividade.

As tecnologias digitais permitem um grau de interatividade completamente novo. É possível estar em contato com alguém com muita afinidade, porém, muito distante. Dessa forma, as pluralidades se tornam mais claras.

O aprendizado do "ser" exemplifica a necessidade desse cidadão estar completo para não se afundar num universo de conhecimentos verdadeiros ou falsos. O senso crítico precisa ser presente ao conviver com essa nova tecnologia de informações contínuas.

\section{Metodologia}

Historicamente, estamos acostumados a ver os discentes a caminho da escola portando seus livros e cadernos. No entanto, com as tecnologias digitais, é normal ver os alunos usarem alguns instrumentos modernos para auxiliar o processo de aprendizagem. É claro que isso é bastante controverso, pois os mais tradicionais defendem a metodologia clássica de educação: lápis, papel e lousa.

Mesmo assim, é comum encontrar escolas que desenvolvem métodos próprios com tecnologia dentro de seus planos pedagógicos. Uma das novidades é a criação de aplicativos para dispositivos móveis que colocam professores e alunos em um mesmo ambiente virtual. Por exemplo, a plataforma LMS, sigla em inglês para Sistema de Gestão de Aprendizagem, por exemplo, é utilizada em algumas escolas.

Em pesquisa bibliográfica e descritiva, buscamos as tecnologias educacionais que se fundamentam nas vantagens ofertadas e que são várias para atingirmos o objetivo que é estudar e descrever a ferramenta Google Classroom.

O aplicativo Google Classroom é uma iniciativa desenvolvida pelo Google, com a intenção de aumentar a integração entre professores e alunos. O serviço é completamente gratuito, e funciona em smartphones e tablets quanto em computadores e notebooks, aumentando sua abrangência em todo o território nacional.

Esta ferramenta permite a realização de aulas virtuais por meio do Google Meet - a plataforma de reuniões (não só de empresas) - além de diversos outros recursos de ensino, como encontros virtuais entre colegas de sala, entrega de avaliações, lista de presença, aplicação de atividade, correção de atividades, índice de acertos e distribuição de notas. 
As funcionalidades da Google Classroom consistem em um mural aberto de comunicação entre os professores e estudantes. Na área, o professor pode publicar e divulgar vídeos, áudios, arquivos de texto, fotos, links e comunicados para os alunos, que por sua vez também podem comentar e interagir com o docente. Há outras funcionalidades que objetivam transformar o aprendizado em uma experiência mais dinâmica. Temos como exemplo, o Classcraft, na qual os professores podem criar jogos para a avaliação de habilidades específicas. Existe também o Quizz, que transforma as provas em jogos divertidos.

O processo de cadastro de discentes e docentes para criar uma conta e acessar a Google Classroom é muito fácil, rápido e completamente digital. Porém, para acessar a plataforma, os mesmos precisam ter uma conta no Google. O roteiro para acessar a plataforma consiste:

- Acessar o site https://classroom.google.com/;

- Inserir seu e-mail de login no Google;

- Clicar em "próxima";

- O acesso já está realizado. Com a plataforma, se pode, caso professor, acessar suas turmas ou criá-las.

A Google Classroom para discentes, especificamente, podem acessar todas as turmas em que estão cadastrados já na primeira página da plataforma. Ao clicar em uma turma específica, os estudantes podem conferir o mural, com todos os conteúdos disponíveis, informações e links. Na aba de atividades, os alunos podem ver os testes e lições já realizadas. Na aba, também é possível checar as notas conseguidas em cada tarefa, além do prazo de entrega e lista de atividades pendentes. O estudante recebe notificações sobre atualizações e atividades no e-mail cadastrado. Pode solicitar também as notificações no celular, para não perder nada. Enfim, na aba "pessoas", os estudantes podem ver todos os integrantes da turma, tirar dúvidas com os professores e interagir com os colegas.

O recurso tecnológico google classroom/sala de aula na rede pública estadual de Mato Grosso, no ano letivo de dois mil e vinte e um, foi oportunizado aos professores e consiste em discutir, especificamente, de maneira conceitual esta ferramenta virtual enquanto propiciadora de um ambiente otimizado no processo ensino-aprendizagem. Uma delas consiste no fato do aluno ter sempre em mãos uma ferramenta que possibilita conhecer as atividades que devem ser entregues e até mesmo estudar acessando provas anteriores de dada disciplina. É necessária também uma metodologia de preparação para os professores, conscientizando-os de que a plataforma é um facilitador do trabalho, e não uma função a mais.

Os benefícios da Google Classroom consistem em sua configuração que é simples; está disponível em quarenta e dois idiomas, permite maior organização de materiais de estudo; promove a comunicação; elimina o excesso de papéis nos domicílios; proporciona maior segurança; promove aconselhamento on-line e; entre outras questões, incentiva discussões, trabalho em grupo e aprendizagem colaborativa.

Sem dúvidas, o fato de usar tablets, notebooks e smartphones no ambiente escolar podem tornar os estudos mais atraentes e agradáveis, no entanto, os cuidados para que a tecnologia não seja objeto de distração precisam ser tomados.

Além disso, as estatísticas também são usadas pelos professores, pois é possível saber em quais questões os alunos tiveram maior dificuldade, direcionando as aulas para sanar as dúvidas mais comuns, de acordo com o perfil do aluno.

Outro fator positivo no uso da ferramenta é o diálogo entre os usuários. O aplicativo educacional permite que se tenha um contato muito mais profundo com aquilo que se está aprendendo, além de possibilitar um diálogo rápido com os professores e com colegas sobre os temas estudados

O conteúdo disponibilizado nesses aplicativos educacionais oferece mais do que um ambiente de interação entre alunos e professores. Podem ainda ajudar nos estudos para vestibulares e para o Exame Nacional do Ensino Médio (Enem). O banco de materiais para estudos inclui fichas de exercícios, vídeos ilustrativos, textos e outras informações que são utilizadas na aula e também material extra que pode ajudar os alunos em outros estudos. 


\section{Resultados e Discussão}

A Google Classroom é uma sala de aula online, que auxilia docentes no gerenciamento de atividades e criação de aulas interativas, ajudando o aluno a aumentar o aprendizado por meio de ferramentas disponíveis na internet.

As aulas na rede estadual de ensino em Mato Grosso foram retomadas em oito de janeiro de dois mil e vinte e um na modalidade não presencial. Foi utilizada a plataforma GSuite resultante da parceria entre a Secretaria Estadual de Educação e o Google For Education por meio de um termo de cooperação técnica entre Seduc-MT e o Google (no período de 2021-2026). A Plataforma GSuite oferece um conjunto de ferramentas (e-mail, drive, classroom, jamboard, meets, maps, tradutor, entre outros) que dão suporte às atividades pedagógicas realizadas na escola durante o referido ano letivo.

Foi oferecida uma conta institucional de e-mail para os profissionais da educação e estudantes nas unidades escolares públicas mato-grossenses e, também, criadas salas de aula virtuais por escola e por turma. A organização das salas virtuais segue o mesmo formato adotado em um ambiente escolar convencional, ou seja, serão membros de uma determinada sala virtual todos os alunos matriculados na respectiva turma, bem como os professores atribuídos na mesma. Exemplo: $1^{\circ}$ ano A/Ensino Médio (são membros todos os professores por componente/disciplina e respectivos estudantes).

A sala de aula é o elemento central de qualquer ambiente escolar. Devido a pandemia do novo coronavírus, as escolas tiveram de ser fechadas e docentes e discentes tiveram de utilizar ferramentas digitais para poder ter a prática de ensinoaprendizagem, que foi realizada à distância. Desse modo, se tornou relevante um ambiente online/virtual que absorvesse todo o processo de trocas e construção do conhecimento. No ano de dois mil e vinte na rede pública estadual mato-grossense foi utilizada a ferramenta Microsoft Teams, porém, não se obteve resultados muito satisfatórios. No ano seguinte, dois mil e vinte um, foi adotado o Google Classroom/Google Sala de Aula.

O aplicativo Google Classroom, se assemelha ao coração humano onde o professor pode utilizá-lo para centralizar suas atividades como também migrar para outras possibilidades. Este recurso virtual facilita o trabalho em equipe e promove uma integração maior entre docentes e discentes. O docente tem diversas opções de atuação: distribuir tarefas e dar devolutivas, desenvolver atividades, abrir a agenda do discente por meio da referida ferramenta. Também tem o recurso de marcar atividades síncronas e reuniões virtuais podendo unir todas as outras ferramentas do referido aplicativo"

"Inicialmente, por parte dos alunos ocorreu um impacto e uma euforia para o uso da ferramenta Google Classroom", foi a percepção pessoal enquanto profissional atuante na rede estadual de Mato Grosso (MT) ao lecionar a disciplina de Português no Ensino Médio. Os docentes e discentes tiveram uma conta institucional do Google, com amplo acesso ao pacote de ferramentas direcionadas ao ambiente educacional. Porém, essa movimentação não empolgou logo de início os alunos. Houve muita resistência por parte dos alunos no uso do e-mail institucional. Neste momento, ficou evidente que os mesmos não tinham domínio com ferramentas educacionais e utilização de e-mail. Expressões como "e-mail institucional" e "anexar" foram termos totalmente desconhecidos pelos discentes.

A docente X, colega na rede estadual mato-grossense, na disciplina de Química para o Ensino Médio em Cuiabá/MT, enfrentou as mesmas dificuldades. De acordo com a professora alguns alunos desconheciam que tinham um gmail no aparelho celular para acessar a Google Classroom como também a negação do uso do e-mail fornecido pela Secretaria de Educação do Estado, pois eles afirmavam que o mesmo não vinha com o nome deles, e sim, com o número de identificação do sistema da Secretaria do Estado. Além destas questões, foi observada a problematização com senha de acesso como também a utilização da plataforma pelo celular. Segundo os alunos, a visão no celular é diferente da visão no computador.

Desta maneira, nós, docentes que já possuíamos alguma experiência com a Google Classroom investimos em um letramento tecnológico/virtual, para, posteriormente, iniciar as atividades virtuais. Foi imprescindível ensinar a linguagem tecnológica. Foi realizada a montagem e envio de tutoriais, com explicações passo a passo, enfim, traduzindo cada palavra e cada ferramenta. Também foi realizado atendimento via whatsapp e por vídeo-chamadas, detalha a professora X. Foi iniciado o 
trabalho pedagógico com vídeo-aulas via Google Meet. Com esta ferramenta foi explicado aos alunos como obter acesso aos prazos de entrega, atividades, materiais como também foi deixado postado na Google Classroom das salas de aula online.

De uma forma bem simplificada, com a Google Classroom se cria uma turma em que o professor tem como acesso inicial o nome da sala juntamente de uma imagem de capa e do código da turma. Acima dessa imagem, há quatro abas em que o professor pode observar: Mural, Atividades, Pessoas e Notas.

O Mural desta ferramenta é muito parecida com a do Facebook, pois permite aos docentes realizarem publicações gerais que podem ser acessadas e visualizadas pelos alunos (no ícone de engrenagem no lado superior direito onde o docente tem acesso às configurações bem como editar as funcionalidades do Mural.

Foi notado que o processo de iniciar os trabalhos com a Google Sala de aula se mostrou desafiador por envolver muitas potencialidades. Os docentes, em sua maioria, afirmaram que o desafio inicial foi o tutorial para auxliar os discentes. Docentes relataram enquanto desafio inicial a elaboração do tutorial para auxiliar os alunos.

A linguagem é o meio possível de exteriorizar o pensamento, de acordo com Vigotsky (2005), no interacionismo social. Para entender sua relação com o interacionismo sociodiscursivo, precisamos prestar atenção à importância que Vygotsky deu à interação para a aprendizagem. Nessa interação, inclusive, sua ênfase maior esteve na mediação da linguagem como ponte entre o pensamento e a ação em convívio social. Esses conceitos são encontrados, em maior ou menor grau, relativizados ou ressignificados, na teoria do discurso e no próprio interacionismo sociodiscursivo.

Por sua vez, Bakhtin (2003) busca contextualizar e definir o enunciado como unidade de comunicação. Para ele, a atividade humana é tão diversa e engloba tantos usos de linguagem, que permite que os integrantes dessas atividades profiram enunciados tanto escritos quanto orais possíveis. O enunciado, assim, é uma realização individual e vinculada à atividade humana. Em sua descrição do enunciado, ele aponta como elementos de sua constituição o conteúdo temático, o estilo e a construção composicional. Assim, essas relações fazem com que o enunciado seja provido de discurso e, ao mesmo tempo, seja sua realização efetiva na sociedade. Isso se dá, naturalmente, nas relações dialógicas mediadas pela linguagem entre sujeitos em sociedade.

Jean-Paul Bronckart, na introdução de sua obra Atividade de linguagem, textos e discursos (2007 [1999], p. 13), explica que as proposições da teoria advêm de "[...] uma psicologia da linguagem orientada pelos princípios epistemológicos do interacionismo social”. Ele ainda acrescenta que a implicação de uma inscrição teórica na psicologia é tomar a unidade de linguagem, em última instância, como uma conduta humana. Essa conduta é tratada como uma ação de significância, uma vez analisada pelo quadro teórico-interacionista-social, daí tratar-se de uma forma de ação e, ainda, ação de linguagem.

De acordo com Chiapinotto (2010) na perspectiva do ISD (Interacionismo Sociodiscursivo), não cabe pensar em educação sem interação social por meio do discurso, uma vez que essa é inerente à ação humana. Assim, o uso que se faz das tecnologias na educação se torna reflexo de uma concepção anterior de aprendizagem e de ação humana em sociedade.

De modo semelhante, o texto produzido por um professor em sala de aula ou publicado na internet, para que seus alunos o acessem, carrega consigo implicações teóricas relevantes. Concebê-lo como um texto didático interativo, em última instância, como uma ação social de linguagem, que repercute em como se dá o processo de ensino e aprendizagem, é um desafio a ser perseguido na educação.

Para que isso se efetive, não somente propostas de reflexão teórica acerca das concepções de como se aprende devem ser formuladas, mas também propostas práticas de aplicação dessas ideias. Oficinas de produção de textos didáticos publicados nos mais diversos suportes, em especial, aqueles ligados às TICs (Tecnologia da Informação e Comunicação), são exemplos de momentos potencialmente produtivos para mudanças em educação.

Para Moran (1999), avançaremos mais se soubermos adaptar os programas previstos às necessidades dos alunos, criando conexões com o cotidiano, com o inesperado, se transformarmos a sala de aula em uma comunidade de investigação. 
Se aprendermos a equilibrar planejamento e a criatividade, a organização e a adaptação a cada situação, a aceitar os imprevistos (no contexto atual, a pandemia), a gerenciar o que podemos prever e a incorporar o novo, o inesperado. Planejamento aberto, que prevê, que está pronto para mudanças, para sugestões, adaptações. Criatividade que envolve sinergia, pôr as diversas habilidades em comunhão, valorizar as contribuições de cada um, estimulando o clima de confiança, de apoio.

Com a flexibilidade procuramos adaptar-nos às diferenças individuais, respeitar os diversos ritmos de aprendizagem, integrar as diferenças locais e os contextos culturais. Com a organização, buscamos gerenciar as divergências, os tempos, os conteúdos, os custos, estabelecemos os parâmetros fundamentais (MORAN, 1999).

Ainda segundo Moran (2010), traçar linhas de ação pedagógica maiores (gerais) que norteiam as ações individuais sem sufocá-las. Respeitar os estilos de dar aula e que dão certo. Respeitar as diferenças que contribuam com o mesmo objetivo. Personalizar os processos de ensino-aprendizagem, sem descuidar o coletivo. Encontrar o estilo pessoal de dar aula, onde nos sintamos confortáveis e consigamos realizar melhor os objetivos.

Com a internet podemos modificar mais facilmente a forma de ensinar e aprender tanto nos cursos presenciais como à distância. São muitos os caminhos, que dependerão da situação concreta em que o professor se encontra: número de alunos, tecnologias disponíveis, duração das aulas, quantidade total de aulas que o professor leciona por semana, apoio institucional. Alguns parecem ser atualmente, mais viáveis e produtivos.

A aquisição da informação, dos dados dependerá cada vez menos do professor. As tecnologias podem trazer hoje dados, imagens, resumos de forma rápida e atraente. O papel do professor - o papel principal - é ajudar o aluno a interpretar esses dados, a relacioná-los, a contextualizá-los. Aprender depende também do aluno, de que ele esteja pronto, maduro, para incorporar a rela significação que essa informação tem para ele, para incorporá-la vivencialmente, emocionalmente. Enquanto a informação não fizer parte do contexto pessoal - intelectual e emocional - não se tornará verdadeiramente significativa, não será aprendida verdadeiramente, declara Moran (2010).

O ponto de partida é o entendimento de como ocorre o aprendizado de cada conhecimento e sua relação com o desenvolvimento do estudante para que a função primeira da escola se realize, ou seja, ofertar ensino de qualidade para todos com a garantia não apenas do acesso, mas, sobretudo da sua permanência até que se complete a educação básica. Essa busca também está ligada aos desafios que a escola, como uma organização complexa, enfrenta na atualidade.

O trabalho em parceria com as instâncias colegiadas e segmentos que delas fazem parte, no sentido de compartilhar decisões e ações a serem propostas para a realidade é sem dúvida uma das primeiras mudanças a serem conquistadas.

O domínio da língua portuguesa é preponderante e oportuniza o acesso ao saber elaborado com o domínio da leitura com entendimento e apropriação da escrita, que cumpra a função social de comunicação com os interlocutores. O desenvolvimento do raciocínio lógico, a capacidade de operar com os números naturais, lidar com as informações, a formação política, o domínio da informática e novas tecnologias aliadas ao trabalho cooperativo, fará da escola um espaço valorizado por todos os segmentos da sociedade.

Ainda desejo ressaltar que acredito na pesquisa da própria prática, como forma de fornecer subsídios preciosos para a melhoria da educação brasileira. Ao se produzir à realidade descobrindo de onde e para que podemos desconstruir antigas representações de escola. Seja na retomada dos conhecimentos, nas revisões da metodologia, na realimentação do planejamento, nos estudos da epistemologia do conhecimento e sua relação com o desenvolvimento e, sobretudo nas formas de avaliar desencadeando a intenção de interromper opções teóricas, metodológicas extremamente tradicionais, que não cabem mais no modelo atual de sociedade. 


\section{Conclusão}

A questão da tecnologia educacional, nos dias de hoje, coloca nos educadores a necessidade de desenvolver habilidades diante das situações rotineiras, pois a instituição social Escola tem sido colocada à prova, taxada como anacrônica reprodutivista e muitas vezes cerceadora de avanços numa perspectiva mais crítica. Aquisições que são conquistadas paulatinamente, uma vez que o Estado tem fronteiras imensas que não possuem ainda alcance político para a internet, o que possibilita grande dificuldade da escola e dos envolvidos - professores e alunos. A tecnologia não é neutra, e como tal, toda ação desenvolvida precisa desencadear um processo contínuo de ação-reflexão-ação e política interessada pela Educação Brasileira, que deveria ser registrada com Letras maiúsculas, ou seja, ser prioridade pelos meios oficiais, assim como a saúde.

De acordo com relato de um aluno da rede pública estadual de Mato Grosso, "o aplicativo Google classroom é abrangente e interessante e permite que meu desempenho nas provas seja melhor", justifica o estudante que acessa o programa pelo menos uma vez por dia.

A adoção da plataforma educacional possibilita o uso de recursos didáticos variados que permitem uma participação ativa do aluno em seu processo de ensino-aprendizagem, tornando-o mais significativo e consistente. Dessa forma, o uso de aplicativos educacionais pode ser mais uma ferramenta para quem deseja estudar utilizando a internet.

Seu projeto pedagógico tecnológico deve priorizar aspectos importantes como uma avaliação com sentido libertador avaliando não apenas a quantidade de conhecimento adquirido, mas, sobretudo a qualidade estabelecida através de critérios claros, pré-estabelecidos nos momentos de planejamento. Critérios que levem ao desenvolvimento da consciência crítica dos estudantes e, sobretudo usar a ferramenta tecnológica como elemento relevante do trabalho realizado.

A partir do estudo realizado se sugestiona a abordagem futura de temas relacionados à prática pedagógica como: "Defasagem na formação docente com o uso da tecnologia digital na práxis metodológica"; "sistema educacional e tecnologias digitais"; "tecnologia, discente e ensino: o que muda?". Os temas sugestionados buscam aprofundar um assunto que está apenas em seu início na abordagem didático/científica, possuindo uma ampla e inesgotável opção de pesquisas acerca do assunto.

\section{Referências}

Almeida, Maria Elizabeth Bianconcini de. (2000). Informática e formação de professores. ProInfo. v. 2. Secretaria de Educação a Distância. Brasília: Ministério da Educação, Seed.

Araújo, R. S. de. (2005). Contribuições da Metodologia WebQuest no Processo de letramento dos alunos nas séries iniciais no Ensino Fundamental. In: MERCADO, Luís Paulo Leopoldo (org.). Vivências com Aprendizagem na Internet. Maceió: Edufal.

Bacich, L., \& Moran, J. (2018). Metodologias ativas para uma educação inovadora: uma abordagem teórico-prática. Penso Editora.

Bakhtin, Mikhail. (2003). Estética da criação verbal. Introd. e trad. De Paulo Bezerra. 4. ed. São Paulo: Martins Fontes.

Bello, M. M. S., Capellini, V. L. M. F., \& Ribeiro, J. A. G. (2018). A Aprendizagem Cooperativa No Cenário Educacional Acadêmico Brasileiro. Nuances: estudos sobre Educação, 29(1).

Bello, M. M. S., Capellini, V. L. M. F., \& Ribeiro, J. A. G. (2013). Questões de estilística no ensino da língua. Org. e notas da edição russa Serguei Botcharov e Liudmila Gogotichvíli. Trad., Posfácio e Notas Sheila Grillo e Ekaterina Vólkova Américo. São Paulo: Editora 34.

Brasil. Ministério da Educação. (2020). Base Nacional Comum Curricular. Brasília. http://basenacionalcomum.mec.gov.br/.

Bronckart, Jean-Paul. (2006). Atividade de linguagem, discurso e desenvolvimento humano. Org. de Anna Rachel Machado e Maria de Lourdes Meirelles Matencio. Trad. de Anna Rachel Machado et al. Campinas: Mercado de Letras.

Chiapinotto, Diego. (2010). Texto didático na educação a distância [recurso eletrônico]: análise à luz do interacionismo sociodiscursivo/Diego Chiapinotto. Caxias do Sul, RS: Educs.

Estrela, C. (2018). Metodologia científica: Ciência, Ensino, Pesquisa. Editora Artes Médicas.

Kenski, V. M. (1999). Novas tecnologias: o redimensionamento do espaço e do tempo e os impactos no trabalho docente. Revista Brasileira de Educação. n.08, p. 58 -71 mai/ago. 1998. LÉVY, Pierre. Cibercultura. São Paulo: Editora 34. 
Research, Society and Development, v. 10, n. 11, e390101119751, 2021

(CC BY 4.0) | ISSN 2525-3409 | DOI: http://dx.doi.org/10.33448/rsd-v10i11.19751

Kenski, V. M. (1993). As tecnologias da inteligência: o futuro do pensamento na era da informática. Editora 34.

Koche, J. C. (2011). Fundamentos de metodologia científica: teoria da ciência e iniciação à pesquisa. Vozes.

Lévy, Pierre. (1999). Cibercultura. Editora 34.

Ludke, M. \& Andre, M.E.D.A. (2013). Pesquisas em educação: uma abordagem qualitativa. E.P.U.

Mercado, Luiz Paulo Leopoldo. (1999). Formação continuada de professores e novas tecnologias. EDUFAL.

Moran, J. M. (1999). Internet no ensino. Comunicação \& Educação. V.(14); p. 17-26.

Moran, J. M. (2007). A educação que desejamos novos desafios e como chegar lá. Papirus.

Moran, J. M. (2004). Texto publicado nos anais do $12^{\circ}$ Endipe - Encontro Nacional de Didática e Prática de Ensino, in ROMANOWSKI, Joana Paulin et al (Orgs). Conhecimento local e conhecimento universal: Diversidade, mídias e tecnologias na educação. vol 2, Curitiba, Champagnat, páginas 245-253

Moran, J. M, Masetto, M, Behrens, M. (2003). Novas tecnologias e mediação pedagógica. (6. ed.) Papirus.

Moran, J. M. (2000). Ensino e aprendizagem inovadores com tecnologias. Informática na educação: teoria \& prática, 3 (1), 137-144. https://doi.org/10.22456/1982-1654.6474.

Paula \& Stafuzza (Orgs). (2013). Círculo de Bakhtin: pensamento interacional. Mercado das Letras.

Pereira A. S.; et al. (2018). Metodologia da pesquisa científica. [e-book grátis].. Ed. UAB/NTE/UFSM.

Perrenoud, Philippe. (nov. 1999/jan.2000). Não há competências sem saberes. Pátio - Revista Pedagógica. Artmed.

Pires, C. S. \& Veiga, A.M. R. (2020). Costurando possibilidades na complexidade da docência: a bricolagem na trajetória auto(trans)formativa. Revista Research, Society and Development. 9. 4. e32942735. ISSN 2525-3409. 971-982.

Ponzo, Augusto. (2008). A Revolução Bakhtiniana. Contexto.

Popenga, M. ; et al. (2021). Da Paz no Currículo Escolar.301-315.

Soares, M. (2004). Letramento e alfabetização: as muitas facetas. Revista Brasileira de Educação, São Paulo, (25), p. 5- 17.

Soares, M. (2002). Português: uma proposta para o letramento: Moderna.

Soares, M. (1998). Letramento: um tema em três gêneros. (2 ed.) Autêntica.

Tondin, C. F.\& Kroth G.\& Junges. S. A. \& Teresinha. C. (2019). O Conhecimento Do Conhecimento: Uma Estratégia Da Escola Para Ensinar a Viver, Revista Contexto \& Educação.34.107.5-18.

Vygotsky, L.S. (1989). A formação social da mente: Interação entre aprendizado e desenvolvimento. Editora Ltda. Martins Fontes.

Yin, R.K. (2015). O estudo de caso. Bookman. 